\title{
The sexual harassment of female active-duty personnel: Effects on job satisfaction and intentions to remain in the military
}

\author{
Heather Antecol ${ }^{\mathrm{a}, *}$, Deborah Cobb-Clark ${ }^{\mathrm{b}, 1}$ \\ a Claremont McKenna College, Department of Economics, 500 E. Ninth Street, \\ Claremont, CA 91711, USA \\ ${ }^{\mathrm{b}}$ Social Policy Evaluation, Analysis and Research Centre, and Economics Program, \\ Research School of Social Sciences, Australian National University, ACT 0200, Australia
}

Received 10 March 2003; received in revised form 3 April 2004; accepted 4 November 2004 Available online 24 August 2005

\begin{abstract}
This paper examines the relationship between sexual harassment and the job satisfaction and intended turnover of active-duty women in the US military. Using single-equation probit models, we find that experiencing a sexually harassing behavior is associated with reduced job satisfaction and heightened intentions to leave the military. However, bivariate probit results indicate that failing to control for individuals' unobserved, time-invariant characteristics leads single-equation estimates to be overstated. Similarly, controlling for women's views about whether they have been sexually harassed reduces the single-equation estimates of the effect of the harassing behavior itself on job satisfaction and intentions to leave the military.

(c) 2005 Elsevier B.V. All rights reserved.
\end{abstract}

JEL classification: $\mathrm{J} 16 ; \mathrm{J} 28$

Keywords: Job satisfaction; Sexual harassment; Military employment

\footnotetext{
* Corresponding author. Tel.: +1 909607 7140; fax: +1 9096218249.

E-mail addresses: heather.antecol@ claremontmckenna.edu (H. Antecol), dcclark@ coombs.anu.edu.au (D. Cobb-Clark).

1 Tel.: +61 26125 3267; fax: +61 261250182.
}

0167-2681/\$ - see front matter @ 2005 Elsevier B.V. All rights reserved. doi:10.1016/j.jebo.2004.11.006 


\section{Introduction}

In 1995, approximately 195,000 women (13 percent of the total force) were on active-duty in the US military. This represents a six-fold increase since 1973 when the all-volunteer force was established (DoD, 1996). Intrinsic differences between military and civilian employment make sexual harassment a particularly salient issue for the US military. Military personnel often live on bases and are on duty $24 \mathrm{~h}$ /day. This high degree of proximity can blur professional and personal relationships and may increase both the incidence and subsequent costs of sexual harassment (Department of Defense, DoD). ${ }^{2}$ In particular, sexual harassment has been linked to a reduction in unit cohesion and combat readiness (Rosen and Martin, 1997), and some have predicted that in the future the military may find "the equal opportunity climate of its units is one of its primary criteria of mission effectiveness" (Knouse, 1991, p. 386).

Our objective is to examine the relationship between sexual harassment, job satisfaction and intended turnover of active-duty women in the Armed Forces. We begin by incorporating measures of unwanted gender-related behaviors into single-equation models of job satisfaction and intentions towards future military employment. This allows us to compare our results directly to those in the literature. This strategy, however, implicitly assumes that reports of sexually harassing behaviors are exogenous, which is unlikely. In particular, unobserved heterogeneity may influence reports of sexually harassing behaviors on the one hand and reported satisfaction with and intentions to remain in military employment on the other. We therefore adopt two alternative strategies for accounting for the role of unobserved characteristics. First, we specify a bivariate probit model that accounts for any correlation between the error terms in sexual harassment and job satisfaction equations. Second, we explicitly control for women's views about whether they have in fact been sexually harassed.

Overall, 70.9 percent of active-duty women reported experiencing some type of sexually harassing behavior in the previous 12 months. Single-equation estimates indicate that sexually harassing behavior is associated with reduced job satisfaction and heightened intentions to leave the military. However, failing to control for individuals' unobserved, time-invariant characteristics (such as personality) causes single-equation estimates to be overstated. Bivariate probit results indicate that sexually harassing behavior does not significantly increase dissatisfaction with military employment once the correlation in unobserved factors associated with reporting a sexually harassing behavior and job satisfaction are taken into account. Similarly, directly controlling for women's views about whether they have been sexually harassed substantially reduces the estimated negative effect of the behavior itself on job satisfaction and indicates that there is, in general, no significant effect of sexually harassing behaviors on intentions to remain in military employment. Perceptions of harassment are driven by the unwanted, gender-related behaviors that women experience as well as by institutional arrangements (including the availability of training and formal complaint channels) in the workplace. Women who view their experiences as sexual harassment

\footnotetext{
${ }^{2}$ The US Merit Systems Protection Board (USMSPB), for example, estimates that between 1992 and 1994 sexual harassment cost the Federal Government US\$ 327 million (USMSPB, 1995). See Schneider et al. (1997) and Fitzgerald et al. (1997) regarding the incidence and consequences of sexual harassment in the workplace.
} 
suffer additional consequences over and above those associated with the behavior itself. This is at odds with previous evidence that women exposed to sexually harassing behaviors report similar negative consequences whether or not they label their experiences as sexual harassment (Magley et al., 1999).

In the next section, we summarize the previous literature on the job satisfaction, intentions to quit, and the role of sexual harassment. Section 3 provides the details of the data used in the analysis, while Section 4 examines the determinants of reported unwanted gender-related behaviors in military employment. Subsequently, the estimation results from the singleequation models are discussed. The potential endogeneity of reported sexual harassment is examined in Section 6, while our conclusions are presented in Section 7.

\section{Job satisfaction, intentions to quit, and the role of sexual harassment}

Though economists first considered the relevance of job satisfaction for economic models 25 years ago (Hamermesh, 1977; Freeman, 1978), in the intervening years the study of job satisfaction has mainly been the purview of psychologists and sociologists. Economists have had relatively little to say about the matter. ${ }^{3}$ In large part this stems from the ambivalence that economists feel towards analyzing subjective information. However, in recent years many have noted renewed interest on the part of economists in studying subjective outcomes generally (Clark, 1996) and job satisfaction in particular (Heywood and Wei, in press; Shields and Ward, 2001). Consequently, there is a growing economics literature assessing the determinants of job satisfaction and the implications of job satisfaction for other outcomes of interest. ${ }^{4}$

Understanding the effect of sexual harassment on job satisfaction is of interest because job satisfaction is a measure of overall well-being (Clark, 1996, 1997) as well as an important predictor of individual behavior. In particular, the psychology literature provides evidence that low job satisfaction is correlated with increased absenteeism (Clegg, 1983), lower worker productivity (Mangione and Quinn, 1975), and increased incidence of mental and physical health problems (Locke, 1976). More importantly for our purposes here, job satisfaction is also related to both intentions to quit (Shields and Wheatley Price, 2002; Shields and Ward, 2001; Laband and Lentz, 1998; Gordon and Denisi, 1995) and actual quit behavior (Kristensen and Westergård-Neilsen, 2004; Clark, 2001; Bertrand and Mullainathan, 2001; Clark et al., 1998; Freeman, 1978) with estimates derived from panel data demonstrating that the causality runs from job satisfaction to future quitting behavior.

Of course any study of job satisfaction relies on the existence of some commonly perceived notion of what it means to be "satisfied". While it is implausible that all individuals would scale their responses in the same way, systematic differences in reported levels of

\footnotetext{
${ }^{3}$ Similarly, economists have generally had relatively little to say about employment-related sexual harassment. In particular, although several theoretical models of labor market discrimination exist in the economics literature, corresponding models of sexual harassment are notoriously absent. The exception is Basu $(2002,2003)$ who models the circumstances under which it is sensible to ban sexual harassment.

${ }^{4}$ See Clark (1996), Clark and Oswald (1996), Heywood and Wei (in press), and Shields and Ward (2001) for reviews.
} 
job satisfaction among different groups of workers suggest that individuals' reports are not completely idiosyncratic (Clark, 1997). ${ }^{5}$ Women and Blacks report higher levels of job satisfaction even though on many objective measures their jobs are worse, a finding that is thought to result from the fact that these groups have lower expectations (Bartel, 1981; Clark, 1997). Job satisfaction is also systematically related to job characteristics such as union status or establishment size (Shields and Ward, 2001; Heywood and Wei, in press).

Despite the growing job satisfaction literature, few studies have explicitly examined the effect of sexual harassment on job satisfaction and intended turnover of female employees. ${ }^{6}$ One exception is Laband and Lentz who find that female lawyers are more likely to be dissatisfied with and intend to leave their jobs if they also report experiencing sexual harassment. ${ }^{7}$ Laband and Lentz, however, did not explicitly address the potential endogeneity of reported sexual harassment, leaving open the question of what role unobserved heterogeneity might play in driving the results.

\section{Data}

We examine the effect of sexual harassment on the job satisfaction and intended turnover of active-duty women in the US Armed Forces using data from the 1995 Status of the Armed Forces Surveys: Form B-Gender Issues conducted by the US Department of Defense (DoD). The data generalize to men and women in the Army, Navy, Marine Corps, Air Force, and Coast Guard with at least six months of active-duty service who were not flag rank officers. Non-proportional, stratified random sampling was used to ensure adequate numbers of women for analysis. Questionnaires were mailed to sample members, and the overall response rate was 58 percent (Bastian et al., 1996; Hay and Elig, 1999). ${ }^{8}$ Although the data generalize to all active-duty personnel, we focus on a final sample of 19,467 activeduty women with non-missing values for all of the variables of interest.

Women were asked which of 24 unwanted gender-related behaviors they had experienced in the previous 12 months. These behaviors ranged from being subjected to offensive sexist remarks and being told sex jokes to experiencing unwanted physical contact and sex without consent. These 24 data items can be combined into 5 categories: (1) sexist behavior, (2) crude or offensive behavior, (3) unwanted sexual attention, (4) sexual coercion, and (5) sexual assault. ${ }^{9}$ Given our interest in sexual harassment, we confine our attention to categories $2-4$

\footnotetext{
${ }^{5}$ Clark (1997) also points to the fact that psychologists and sociologists have repeatedly validated job satisfaction measures as evidence that it is useful to analyze job satisfaction.

${ }^{6}$ See Fitzgerald et al. (1997) who reviews the psychology literature on sexual harassment and job satisfaction.

7 Shields and Wheatley Price use both single- and multiple-equation models to study racial harassment, job satisfaction, and intentions to remain in the British nursing profession. Both job dissatisfaction and intentions to quit increase with racial harassment.

${ }^{8}$ Weights provided by the DoD adjust for non-response in addition to the sampling frame (Bastian et al.).

9 The questions included in Form B were based on a survey instrument (The Sexual Experiences Questionnaire or SEQ) developed by psychologists at the University of Illinois (Lancaster, 1999). Fitzgerald et al. (1999) report on the validity and reliability of the survey instrument and discuss options for scoring responses. Arvey and Cavanaugh (1995) point to the SEQ as a "particularly sound" methodology for studying sexual harassment.
} 
and define four types of sexually harassing behavior: (1) crude or offensive behavior, (2) unwanted sexual attention, (3) sexual coercion, and (4) any of the above. ${ }^{10}$ Thus, following standard practice in this literature, our notion of sexual harassment is based upon one or more experiences of unwanted gender-related behavior. It does not rely upon individuals reporting themselves to have been "sexually harassed" and does not necessarily fit with legal definitions. ${ }^{11}$

Table 1 shows the specific behaviors that form each type of unwanted gender-related behavior. Overall, 70.9 percent of active-duty women reported experiencing sexually harassing behavior. This incidence is high relative to rates among civilian workers, though differences in survey design and the behaviors considered to be sexual harassment make direct comparisons difficult. Most importantly, whereas our data reflect experiences in the previous 12 months, most surveys of civilian workers ask about the previous two years. In 1994, 44 percent of women employed by the US Federal Government reported experiencing unwanted sexual attention at some point in the previous 24 months (USMSPB). Furthermore, 68 percent of women employed in a large, private-sector firm and 63 percent of women employed at a mid-western university experienced sexual harassment over a twoyear period (Schneider et al.). Similarly, two-thirds of female lawyers in private practice and almost half of female lawyers employed in corporations and public agencies reported experiencing sexual harassment in the previous two years (Laband and Lentz).

Crude or offensive behavior is the most frequently reported form of unwanted genderrelated behavior for women on active-duty (69.2 percent), with unwanted sexual attention (40.8 percent), and sexual coercion (12.3 percent) occurring less frequently. One in two women said that in the past year they were often told jokes about sex. Almost 40 percent of respondents reported having been whistled or stared at in a sexual way, experiencing unwelcome sex discussions, or being subjected to sexual remarks. Furthermore, approximately one in four active-duty women reported that they had repeatedly been asked for dates after declining or touched in a way that made them feel uncomfortable. Finally, 7.6 percent said that it had been implied that they would be rewarded if they had sex while 7.0 percent responded that they had been badly treated because they had refused to have sex with someone. ${ }^{12,13}$

\footnotetext{
${ }^{10}$ Sexist behavior includes being treated differently or demeaned because of one's sex, while sexual assault includes rape and attempted rape. As such, neither category would usually be considered sexual harassment per se.

11 Fitzgerald et al. (1999) argue that as it is impossible to determine who would meet legal criteria without a judicial review, a legal definition would be impractical for most research and policy purposes. Definitions based upon the filing of a complaint are also flawed because sexual harassment often goes unreported, while definitions based on perceptions of having been harassed introduce subjectivity into the analysis (see also USMSPB, 1995).

12 Not surprisingly, reports of sexual harassing behaviors are much more common among women than among men (Antecol and Cobb-Clark, 2001). While almost three-quarters of women reported experiencing sexual harassment, only one-third of male active-duty personnel said that they had experienced any sexually harassing behaviors in the previous 12 months.

13 Despite higher reports among female active-duty personnel, male and female reports of sexual harassment by service type are positively correlated $(0.8260)$ and significant $(p=0.000)$. This is consistent with Laband and Lentz who find a positive correlation of $0.9126(p=0.000)$ between male reports of observed sexual harassment against women and women's reports of sexual harassment. They argue that this positive correlation suggests that female reports coincide with "actual" sexual harassment.
} 
Incidence of sexually harassing behaviors, job satisfaction, and likelihood of remaining in the military

\begin{tabular}{|c|c|c|c|c|c|}
\hline & $\begin{array}{l}\text { Incidence of } \\
\text { behavior }\end{array}$ & (Very) dissatisfied & (Very) satisfied & $\begin{array}{l}\text { (Very) unlikely } \\
\text { to remain }\end{array}$ & $\begin{array}{l}\text { (Very) likely } \\
\text { to remain }\end{array}$ \\
\hline Total & & 0.187 & 0.626 & 0.280 & 0.579 \\
\hline Crude/offensive behavior & 0.692 & 0.214 & 0.578 & 0.298 & 0.550 \\
\hline (1) Been often told sex jokes & 0.490 & 0.233 & 0.554 & 0.302 & 0.541 \\
\hline (2) Whistled at in sexual way & 0.388 & 0.225 & 0.549 & 0.312 & 0.533 \\
\hline (3) Unwelcome sex discussions & 0.395 & 0.247 & 0.531 & 0.315 & 0.522 \\
\hline (4) Sexual remarks in public or private & 0.400 & 0.252 & 0.531 & 0.306 & 0.535 \\
\hline (5) Remarks on body/sex acts & 0.367 & 0.259 & 0.520 & 0.326 & 0.506 \\
\hline (6) Offensive sexual gestures & 0.332 & 0.247 & 0.536 & 0.308 & 0.530 \\
\hline (7) Stared at in a sexual way & 0.395 & 0.236 & 0.544 & 0.313 & 0.533 \\
\hline (8) Harasser exposed self & 0.047 & 0.281 & 0.492 & 0.328 & 0.504 \\
\hline Unwanted sexual attention & 0.408 & 0.234 & 0.544 & 0.308 & 0.522 \\
\hline (1) Attempts to establish sex relationship & 0.284 & 0.251 & 0.514 & 0.321 & 0.508 \\
\hline (2) Asked for dates after you said no & 0.269 & 0.248 & 0.520 & 0.316 & 0.503 \\
\hline (3) Touch made you uncomfortable & 0.232 & 0.257 & 0.522 & 0.303 & 0.534 \\
\hline Sexual coercion & 0.123 & 0.285 & 0.458 & 0.330 & 0.476 \\
\hline (1) Implied reward if you have sex & 0.076 & 0.276 & 0.470 & 0.317 & 0.494 \\
\hline (2) Scared if you do not cooperate with sex & 0.056 & 0.324 & 0.405 & 0.312 & 0.463 \\
\hline (3) Treated you badly because refused sex & 0.070 & 0.327 & 0.404 & 0.343 & 0.445 \\
\hline (4) Implied faster promotion for sex & 0.034 & 0.383 & 0.410 & 0.332 & 0.482 \\
\hline (5) Fear treated badly if no sex & 0.043 & 0.347 & 0.376 & 0.343 & 0.421 \\
\hline (6) Offer sex to you in return for favor & 0.023 & 0.374 & 0.430 & 0.305 & 0.526 \\
\hline No behavior reported & 0.291 & 0.124 & 0.737 & 0.237 & 0.644 \\
\hline
\end{tabular}

Notes: Sampling weights used. The number of observations for the total sample, the sample who reported crude/offensive behavior, unwanted sexual attention, sexual coercion, and no behavior are 19,467, 12,827, 6884, 1806, and 6278, respectively. The number of observations for the eight components of crude/offensive behavior are: (1) 9187, , (2) 6434 , (3) 6735 , (4) 7147, (5) 5984, (6) 5751, (7) 6784, and (8) 751. The number of observations for the four components of unwanted sexual attention are: (1) 4528, (2) 4132, (3) 3925, and (4) 2310. The number of observations for the six components of sexual coercion are: (1) 1114, (2) 832, (3) 983, (4) 549, (5) 631, and (6) 381 . 
Respondents were also asked how satisfied they were with military life. ${ }^{14}$ Specifically, individuals were asked, first, how satisfied are you with your job as a whole? Second, suppose that six months from now you will be faced with the decision about whether to remain in military service. Assuming that you could remain, how likely is it that you would choose to remain in the military? ${ }^{15}$ We consider two alternative discrete measures of job satisfaction. "(Very) dissatisfied" equals 1 for individuals reporting that they are either dissatisfied or very dissatisfied with their job as a whole and 0 otherwise. "(Very) satisfied" equals 1 only for those women reporting that they are either satisfied or very satisfied with their jobs. Similar measures are defined for intentions to remain in military employment.

Table 1 (row 1) indicates that satisfaction with military employment is generally high with 62.6 percent of women reporting that they are (very) satisfied with their jobs and 57.9 percent saying that they are (very) likely to remain in the military. Not surprisingly, sexual harassment is associated with lower job satisfaction and an increased probability of leaving the military. Furthermore, job dissatisfaction and intended job turnover are highest among female active-duty personnel experiencing sexual coercion.

\section{The determinants of sexually harassing behaviors}

Who reports experiencing unwanted gender-related behaviors? To consider this, we model the propensity to report sexually harassing behaviors $\left(H^{*}\right)$ as

$$
H_{i j}^{*}=X_{i} \beta_{j}+\varepsilon_{i j}
$$

where $\varepsilon_{i j} \sim N(0,1), i$ indexes individuals, and $j$ indexes three discrete measures of reported sexual harassment. "Any sexually harassing behavior" equals 1 if a woman reports any sexually harassing behavior (including crude/offensive behavior, unwanted sexual attention, or sexual coercion) and 0 otherwise. "Sexual attention/coercion" equals 1 if a woman reports either unwanted sexual attention or sexual coercion. "Sexual coercion" equals 1 only for women reporting some form of sexual coercion. These three measures account for the differing degrees of severity of sexual harassment evident in Table $1 .^{16}$

Our model includes a vector $\left(X_{i}\right)$ of those demographic (marital status and race) and human capital characteristics (education and years of active-duty) related to the propensity to report sexual harassment. Additionally, $X_{i}$ includes current job characteristics (branch of service and pay level) along with indicators for current supervisor status, serving aboard a ship, being US based, and on training-related assignment. As male-dominated workplaces are associated with higher levels of sexual harassment (USMSPB, 1995; Fitzgerald et al., 1997), $X_{i}$ also includes an indicator of the gender of a woman's supervisor as well as

\footnotetext{
14 The data also include information on demographic, human capital, job, workplace, and duty station characteristics.

15 Possible responses to the first question include very dissatisfied, dissatisfied, neither, satisfied, and very satisfied. Possible responses to the second question include very unlikely, unlikely, neither, likely, and very likely.

16 Because incidents of sexual harassment are not independent, random events, the severity and frequency of sexual harassment are related (Magley et al.).
} 
measures of the gender composition of the military occupation and duty station in which she is employed. ${ }^{17}$

Finally, organizational factors may also facilitate or inhibit the occurrence of sexual harassment (Williams et al., 1999; Rosen and Martin, 1997). Given this we control for respondents' recent, sexual-harassment-related training as well as the existence of a sexual harassment office, publicized complaint channels, and a sexual harassment hotline at the duty station. ${ }^{18}$ The probability that a woman reports a sexually harassing behavior $(H)$ is given by

$$
\operatorname{Pr}\left(H_{i j}=1\right)=\operatorname{Pr}\left(X_{i} \beta_{j}+\varepsilon_{i j}>0\right)=\Phi\left(X_{i} \beta_{j}\right)
$$

where $\Phi$ is the standard normal cumulative density function.

Table 2 reports the estimated determinants of: (1) sexual attention/coercion, (2) sexual coercion, and (3) any sexually harassing behavior. To facilitate interpretation, we report the marginal effects (evaluated at means) and standard errors (calculated using the delta method). ${ }^{19}$ Results indicate that being married is associated with experiencing fewer sexually harassing behaviors. For example, married women are 8.3 (14.5) percentage points less likely to report any sexually harassing behavior (sexual attention/coercion) than are their single counterparts. Interestingly, relative to Whites, Blacks are significantly more likely to report sexual coercion, though they are less likely to report experiencing unwanted gender-related behaviors generally.

However, with the exception of sexual coercion, reports of unwanted gender-related behaviors significantly decrease with years of duty at a decreasing rate. Reports of any sexually harassing behavior significantly increase with education. ${ }^{20}$ For example, female active-duty personnel who have some college education (but less than a BA) are 7.8 percentage points more likely to report any sexually harassing behavior. This is consistent with other evidence that the typical victim of sexual harassment is college educated (see USMSPB).

The incidence of unwanted gender-related behaviors is significantly higher in the Army relative to other services, with the exception of Marines who report similar rates of sexual harassment generally and sexual attention/coercion in particular. For instance, women in the Coast Guard are 8.7 percentage points less likely to report any sexually harassing behavior and 5.2 percentage points less likely to report sexual coercion than women in the Army. As the overall rate of sexual coercion is 12.3 percent (see Table 1), this constitutes a large difference in the relative probabilities of reporting sexual coercion. Those at the very bottom of the pay scale are also more likely to report sexual attention/coercion (20.3 percentage points) than are women at the top of the pay scale. Once women move beyond the first three or four rungs of the pay ladder there is little difference in their probability of reporting sexually harassing behaviors.

\footnotetext{
17 Respondents indicated whether their work groups were male-dominated, female-dominated or of equal gender mix (the omitted category) and whether they were in a military occupation not usually held by persons of their gender.

18 Training is coded as 1 if the individual received more than $1 \mathrm{~h}$ of sexual harassment training and 0 otherwise.

19 All estimation was performed in STATA 7.0. Coefficient estimates are available from the authors upon request.

20 The omitted education category is that with no college education.
} 
Table 2

Determinants of sexually harassing behaviors by type of behavior (probit marginal effects and standard errors)

\begin{tabular}{|c|c|c|c|}
\hline & $\begin{array}{l}\text { Any sexually } \\
\text { harassing behavior }\end{array}$ & Sexual attention/coercion & Sexual coercion \\
\hline \multicolumn{4}{|c|}{ Demographic and human capital characteristics } \\
\hline Married & $\begin{array}{c}-0.083^{* * *} \\
(0.007)\end{array}$ & $\begin{array}{l}-0.145^{\text {*** }} \\
(0.007)\end{array}$ & $\begin{array}{c}-0.045^{\text {**** }} \\
(0.004)\end{array}$ \\
\hline Black & $\begin{array}{c}-0.043^{* * *} \\
(0.009)\end{array}$ & $\begin{array}{c}0.003 \\
(0.009)\end{array}$ & $\begin{array}{l}0.013^{* * * *} \\
(0.004)\end{array}$ \\
\hline Hispanic & $\begin{array}{c}0.010 \\
(0.018)\end{array}$ & $\begin{array}{c}0.008 \\
(0.019)\end{array}$ & $\begin{array}{c}0.003 \\
(0.010)\end{array}$ \\
\hline Other & $\begin{array}{c}0.011 \\
(0.016)\end{array}$ & $\begin{array}{l}0.037^{* *} \\
(0.017)\end{array}$ & $\begin{array}{l}0.024^{* * *} \\
(0.010)\end{array}$ \\
\hline Years of duty & $\begin{array}{l}-0.014^{* * * *} \\
(0.003)\end{array}$ & $\begin{array}{l}-0.016^{* * * *} \\
(0.003)\end{array}$ & $\begin{array}{r}-0.000 \\
(0.002)\end{array}$ \\
\hline Years of duty squared & $\begin{array}{l}0.000^{* *} \\
(0.000)\end{array}$ & $\begin{array}{c}0.000^{*} \\
(0.000)\end{array}$ & $\begin{array}{r}-0.000 \\
(0.000)\end{array}$ \\
\hline \multicolumn{4}{|l|}{ Education } \\
\hline Less than BA & $\begin{array}{l}0.078^{* * * *} \\
(0.011)\end{array}$ & $\begin{array}{l}0.039^{* * *} \\
(0.011)\end{array}$ & $\begin{array}{c}0.007 \\
(0.005)\end{array}$ \\
\hline BA & $\begin{array}{l}0.047^{* * * *} \\
(0.016)\end{array}$ & $\begin{array}{c}-0.000 \\
(0.017)\end{array}$ & $\begin{array}{r}-0.014^{*} \\
(0.008)\end{array}$ \\
\hline Greater than BA & $\begin{array}{l}0.046^{* * * *} \\
(0.017)\end{array}$ & $\begin{array}{r}-0.007 \\
(0.019)\end{array}$ & $\begin{array}{l}-0.021^{* *} \\
(0.009)\end{array}$ \\
\hline \multicolumn{4}{|l|}{ Current job characteristics } \\
\hline Navy & $\begin{array}{c}-0.066^{* * *} \\
(0.011)\end{array}$ & $\begin{array}{l}-0.074^{* * * *} \\
(0.010)\end{array}$ & $\begin{array}{l}-0.040^{* * * *} \\
(0.004)\end{array}$ \\
\hline Marines & $\begin{array}{c}-0.016 \\
(0.014)\end{array}$ & $\begin{array}{c}-0.019 \\
(0.013)\end{array}$ & $\begin{array}{c}-0.020^{* * * *} \\
(0.005)\end{array}$ \\
\hline Air Force & $\begin{array}{c}-0.084^{* * * *} \\
(0.009)\end{array}$ & $\begin{array}{c}-0.089^{* * * *} \\
(0.009)\end{array}$ & $\begin{array}{c}-0.051^{\text {**** }} \\
(0.004)\end{array}$ \\
\hline Coast Guard & $\begin{array}{c}-0.087^{\text {**** }} \\
(0.017)\end{array}$ & $\begin{array}{c}-0.124^{* * * *} \\
(0.014)\end{array}$ & $\begin{array}{c}-0.052^{* * * *} \\
(0.004)\end{array}$ \\
\hline Male supervisor & $\begin{array}{c}0.013 \\
(0.009)\end{array}$ & $\begin{array}{r}-0.004 \\
(0.009)\end{array}$ & $\begin{array}{r}-0.002 \\
(0.005)\end{array}$ \\
\hline \multicolumn{4}{|c|}{ Gender mix of work group } \\
\hline Male dominated & $\begin{array}{l}0.064^{* * * *} \\
(0.010)\end{array}$ & $\begin{array}{l}0.033^{* * *} \\
(0.010)\end{array}$ & $\begin{array}{l}0.025^{* * *} \\
(0.005)\end{array}$ \\
\hline Female dominated & $\begin{array}{c}0.010 \\
(0.011)\end{array}$ & $\begin{array}{c}0.018 \\
(0.013)\end{array}$ & $\begin{array}{l}0.024^{\text {**** }} \\
(0.008)\end{array}$ \\
\hline \multicolumn{4}{|l|}{ Pay scale } \\
\hline E1-E3 & $\begin{array}{l}0.101^{* * * *} \\
(0.023)\end{array}$ & $\begin{array}{l}0.203^{* * *} \\
(0.030)\end{array}$ & $\begin{array}{l}0.176^{* * * *} \\
(0.033)\end{array}$ \\
\hline E4 & $\begin{array}{l}0.133^{* * * *} \\
(0.019)\end{array}$ & $\begin{array}{l}0.211^{* * *} \\
(0.026)\end{array}$ & $\begin{array}{l}0.135^{\text {**** }} \\
(0.026)\end{array}$ \\
\hline E5-E6 & $\begin{array}{l}0.087^{* * * *} \\
(0.018)\end{array}$ & $\begin{array}{l}0.133^{* * * *} \\
(0.021)\end{array}$ & $\begin{array}{l}0.055^{\text {**** }} \\
(0.014)\end{array}$ \\
\hline E7-E9 & $\begin{array}{l}0.055^{* * * *} \\
(0.017)\end{array}$ & $\begin{array}{l}0.104^{* * *} \\
(0.022)\end{array}$ & $\begin{array}{l}0.037^{* * * *} \\
(0.015)\end{array}$ \\
\hline
\end{tabular}


Table 2 (Continued)

\begin{tabular}{|c|c|c|c|}
\hline & $\begin{array}{l}\text { Any sexually } \\
\text { harassing behavior }\end{array}$ & Sexual attention/coercion & Sexual coercion \\
\hline \multirow[t]{2}{*}{ W1 } & 0.047 & $0.061^{*}$ & 0.014 \\
\hline & $(0.031)$ & $(0.038)$ & $(0.023)$ \\
\hline \multirow[t]{2}{*}{$\mathrm{O} 1-\mathrm{O} 3$} & $0.025^{*}$ & $0.034^{*}$ & 0.006 \\
\hline & $(0.015)$ & $(0.018)$ & $(0.011)$ \\
\hline \multirow[t]{2}{*}{ MOS uncommon for gender } & $0.078^{* * * *}$ & $0.075^{* * *}$ & $0.023^{* * *}$ \\
\hline & $(0.010)$ & $(0.012)$ & $(0.006)$ \\
\hline \multirow[t]{2}{*}{ Supervisor } & $0.045^{* * *}$ & $0.046^{* * *}$ & $0.015^{* * *}$ \\
\hline & $(0.008)$ & $(0.008)$ & $(0.004)$ \\
\hline \multirow[t]{2}{*}{ Located in US } & $-0.028^{* * *}$ & $-0.035^{* * *}$ & $-0.011^{* *}$ \\
\hline & $(0.010)$ & $(0.010)$ & $(0.005)$ \\
\hline \multirow[t]{2}{*}{ In training-related duty } & $0.016^{*}$ & 0.005 & $0.014^{* * * *}$ \\
\hline & $(0.009)$ & $(0.009)$ & $(0.005)$ \\
\hline \multirow[t]{2}{*}{ Serving on a ship } & $0.117^{* * * *}$ & $0.083^{* * * *}$ & $0.028^{* *}$ \\
\hline & $(0.017)$ & $(0.021)$ & $(0.012)$ \\
\hline \multicolumn{4}{|l|}{ Duty station has } \\
\hline \multirow[t]{2}{*}{ Sexual harassment hotline } & -0.012 & $-0.030^{* * *}$ & $-0.008^{*}$ \\
\hline & $(0.008)$ & $(0.009)$ & $(0.005)$ \\
\hline \multirow[t]{2}{*}{ Sexual harassment office } & $-0.025^{* * *}$ & $-0.021^{* * *}$ & $0.007^{*}$ \\
\hline & $(0.008)$ & $(0.008)$ & $(0.004)$ \\
\hline \multirow[t]{2}{*}{ Complaint process } & $-0.081^{* * *}$ & $-0.064^{* * *}$ & $-0.040^{* * * *}$ \\
\hline & $(0.009)$ & $(0.010)$ & $(0.005)$ \\
\hline \multirow[t]{2}{*}{ Sexual harassment training } & $-0.038^{* * *}$ & $-0.025^{* * *}$ & $-0.017^{* * *}$ \\
\hline & $(0.008)$ & $(0.008)$ & $(0.004)$ \\
\hline$N$ & 19,467 & 19,467 & 19,467 \\
\hline
\end{tabular}

Note: See the text for variable definitions.

* Significant at less than 10 percent.

** Significant at less than 5 percent.

*** Significant at less than 1 percent.

Unwanted gender-related behaviors are related to the nature of one's current job assignment. Reports of sexually harassing behaviors are lower among women on active-duty in the US than among those stationed overseas. These differences are relatively minor, however, suggesting that the variation in institutions, policies, and social norms reflected in postings overseas have little effect on reports of sexually harassing behavior. Similarly, women currently serving aboard a ship report significantly more sexually harassing behaviors. This is perhaps not surprising given the close quarters that would typically define this type of duty.

Consistent with previous evidence (USMSPB, 1995; Fitzgerald et al., 1997), women working in male-dominated work groups are more likely to report sexually harassing behavior. While research has considered only the dichotomous distinction between maledominated and female-dominated workplaces, we find that women employed in femaledominated work groups are also more likely (2.4 percentage points) to report sexual coercion than those employed in groups with equal gender mixes. Thus, it appears that women employed in the US military may experience more unwanted gender-related behaviors in work groups with unequal gender mixes. 
Finally, sexual-harassment training is associated with fewer reports of sexually harassing behaviors. For instance, women who had had at least $1 \mathrm{~h}$ of sexual harassment training are 3.8 (2.5) percentage points less likely to report experiencing any sexually harassing behavior (sexual attention/coercion) than women having no sexual harassment training. Whether this occurs because training reduces women's propensity to experience actual sexual harassment or because training alters the behaviors that women perceive as sexually harassing is unclear. However, other evidence suggests that sexual harassment training results in broader (rather than narrower) definitions of those behaviors that constitute sexual harassment (Antecol and Cobb-Clark, 2003). Finally, women serving at duty stations with sexual harassment hotlines, offices, or publicized complaint channels are generally less likely to report experiencing sexual harassment. Thus, consistent with previous research, sexual harassment appears to be related to the extent to which the organization is successful in creating a climate in which sexual harassment is not tolerated (Williams et al., 1999; Rosen and Martin, 1997).

\section{Single-equation estimates of the effect of sexually harassing behaviors on job satisfaction and likelihood of remaining in the military}

We begin by assuming that reports of unwanted gender-related behaviors are exogenous to job satisfaction and intended turnover. This assumption will be considered further below. Suppose $D_{i}^{*}$ measures a propensity to report being (dis)satisfied with military employment and (un)likely to remain in the military:

$$
D_{i j k}^{*}=Z_{i} \gamma_{j k}+H_{i j} \delta_{j k}+\eta_{i j k}
$$

where $\eta_{i j k} \sim N(0,1)$ and $k$ indexes the four discrete $(0 / 1)$ outcome measures. Specifically, $D_{i j 1}=1$ for women reporting being (very) dissatisfied with their jobs, $D_{i j 2}=1$ for women reporting being (very) satisfied their jobs, $D_{i j 3}=1$ for women reporting being (very) unlikely, and $D_{i j 4}=1$ for (very) women reporting being likely or very likely to remain in the military. Additionally, $Z_{i}$ is a vector of background variables and $H_{i j}$ are the various measures of sexually harassing behaviors discussed above. ${ }^{21}$ The probability of reporting (dis)satisfied with or (un)likely to remain in military employment is then given by

$$
\operatorname{Pr}\left(D_{i j k}=1\right)=\operatorname{Pr}\left(Z_{i} \gamma_{j k}+H_{i j} \delta_{j k}+\eta_{i j k}>0\right)=\Phi\left(Z_{i} \gamma_{j k}+H_{i j} \delta_{j k}\right) .
$$

Estimated marginal effects (and associated standard errors and $p$-values) are reported in Table $3 .^{22}$ Irrespective of the type of behavior considered, experiencing unwanted genderrelated behavior significantly increases dissatisfaction with and heightens intentions to leave military employment. ${ }^{23}$ Interestingly, sexually harassing behaviors have a larger effect on

\footnotetext{
21 See the notes to Table 3 for a complete list of the variables included in.

22 Marginal effects for the complete model are available from the authors upon request.

23 Similarly, sexually harassing behavior significantly decreases satisfaction with military employment and lowers intentions to remain in the military. Given that our results are of opposite sign (leading to the same substantive conclusions) whether we consider job dissatisfaction and intentions to leave or job satisfaction and intentions to remain, it does not appear to matter how the middle category of responses is treated. Additionally, we also estimated ordered probit models and obtained similar results. These results are available from the authors upon request.
} 
Table 3

The effect of sexually harassing behaviors on job satisfaction (probit marginal effects and standard errors)

\begin{tabular}{|c|c|c|c|}
\hline Prob (measure of job satisfaction) & Measure of sexually harassing behavior & $\partial \mathbf{J S} / \partial \mathrm{SH}$ & S.E. \\
\hline (Very) dissatisfied with job ${ }^{\mathrm{a}}$ & Any sexually harassing behavior & $0.053^{* * * *}$ & 0.005 \\
\hline (Very) satisfied with job ${ }^{b}$ & Any sexually harassing behavior & $-0.086^{* * *}$ & 0.007 \\
\hline (Very) unlikely to remain ${ }^{c}$ & Any sexually harassing behavior & $0.018^{* * *}$ & 0.007 \\
\hline (Very) likely to remain ${ }^{\mathrm{d}}$ & Any sexually harassing behavior & $-0.033^{* * *}$ & 0.008 \\
\hline (Very) dissatisfied with job ${ }^{\mathrm{a}}$ & Sexual attention/coercion & $0.044^{* * *}$ & 0.006 \\
\hline (Very) satisfied with job ${ }^{b}$ & Sexual attention/coercion & $-0.068^{* * *}$ & 0.007 \\
\hline (Very) unlikely to remain ${ }^{c}$ & Sexual attention/coercion & $0.021^{* * *}$ & 0.007 \\
\hline (Very) likely to remain ${ }^{\mathrm{d}}$ & Sexual attention/coercion & $-0.036^{* * *}$ & 0.008 \\
\hline (Very) dissatisfied with job ${ }^{\mathrm{a}}$ & Sexual coercion & $0.079^{* * *}$ & 0.010 \\
\hline (Very) satisfied with job ${ }^{\mathrm{b}}$ & Sexual coercion & $-0.125^{* * *}$ & 0.013 \\
\hline (Very) unlikely to remain ${ }^{c}$ & Sexual coercion & $0.028^{* *}$ & 0.011 \\
\hline (Very) likely to remain ${ }^{\mathrm{d}}$ & Sexual coercion & $-0.042^{* * *}$ & 0.013 \\
\hline
\end{tabular}

Note: Intentions to remain in the military equations include the following controls: married, Black, Hispanic, other, years of duty, years of duty squared, less than BA, BA, greater than BA, Navy, Marines, Air Force, Coast Guard, male supervisor, male dominated, female dominated, pay categories, MOS uncommon for gender, supervisor, US location, training-related duty, sexual harassment hotline, sexual harassment office, complaint process, and sexual harassment training. Job satisfaction equations include all of the same controls except married. See the text for variable definitions.

a Relative to very satisfied, satisfied, and neither satisfied nor dissatisfied.

b Relative to very dissatisfied, dissatisfied, and neither satisfied nor dissatisfied.

c Relative to very likely, likely, and neither likely nor unlikely.

d Relative to very unlikely, unlikely, and neither likely nor unlikely.

** Significant at less than 5 percent.

*** Significant at less than 1 percent.

job (dis)satisfaction than on intended job change. For example, female active-duty personnel are 5.3 percentage points (28.3 percent) more likely to report they are (very) dissatisfied with their jobs, but only 1.8 percentage points ( 6.4 percent) more likely to report intending to leave the military if they report experiencing any sexually harassing behavior. ${ }^{24}$ Not surprisingly, sexual coercion has the biggest effect on both overall dissatisfaction with and intentions to leave the military.

These findings for women on active-duty in the US military are broadly consistent with the previous results for women working in the civilian labor market (see, for example, Laband and Lentz, 1998; Fitzgerald et al., 1997). Laband and Lentz, for example, report that female lawyers are 50.2 (33.5) percent more likely to report being dissatisfied with their job if they experienced sexual harassment by their superiors (colleagues). Controlling for job satisfaction, Laband and Lentz also find that female lawyers are more than 25 percent more likely to intend to leave their jobs if they are subjected to sexual harassment from their supervisors and colleagues. Interestingly, sexual harassment by clients does not appear to affect overall job satisfaction or intentions to quit. Comparison to our results in Table 3 indicates that unwanted gender-related behaviors have a more detrimental effect on job satisfaction and intentions to remain in the job in the legal profession than in the military.

\footnotetext{
24 The results expressed in percent terms are based on the overall sample averages (see Table 1).
} 


\section{The role of personality traits: accounting for omitted variable bias}

The single-equation estimates discussed above (like previous results in the literature) assume that reports of sexually harassing behaviors are exogenous to reports of job satisfaction and intentions towards future military employment. However, it is unlikely that this is the case. Heterogeneity in individuals' perceptions of, tolerance for, or willingness to report unpleasant events in the workplace is likely to affect both reports of sexually harassing behaviors and women's satisfaction with military employment. ${ }^{25}$ Taking this endogeneity into account would affect the estimated effect of sexually harassing behaviors per se.

To see this, consider the following. Suppose rather than Eqs. (1) and (3), the true model is given by the following:

$$
\begin{aligned}
& H_{i j}^{*}=X_{i} \beta_{j}+A_{i} \alpha_{j}+\varepsilon_{i j}^{\prime} \\
& D_{i j k}^{*}=Z_{i} \gamma_{j k}+H_{i j} \delta_{j k}+A_{i} \varphi_{j k}+\eta_{i j k}^{\prime}
\end{aligned}
$$

where $A_{i}$ is some unobserved aspect of an individual's "personality", "disposition", or "willingness to report" and the other variables are defined as before. The question then becomes how might $\hat{\delta}_{j k}$ given in Table 3 be biased by our failure to control for this in the estimation? The answer to this question depends on the following:

$$
E\left(\hat{\delta}_{j k}\right)=\delta_{j k}+\frac{\operatorname{Cov}\left(H_{i j}, A_{i}\right)}{\operatorname{Var}\left(H_{i j}\right)} \cdot \varphi_{j k} .
$$

If a positive disposition or a high tolerance for negative job situations increases job satisfaction and also reduces the propensity to report sexually harassing behavior, we falsely attribute the effect of this unobserved characteristic to the effect of harassment. This causes the single-equation estimates of the effect of sexually harassing behaviors on the probability of being dissatisfied (see Table 3) to be overstated.

Two strategies are utilized to deal with this problem. First, we specify a bivariate probit model allowing us to take into account any correlation between the error terms in the sexual harassment and job satisfaction equations. This approach has the advantage that we do not have to be specific about what characteristics are being omitted, but suffers from the disadvantage that the results are identified through potentially weak exclusion restrictions. Secondly, we include a proxy for the omitted characteristic directly into the model. This eliminates the need to find sensible exclusion restrictions, but allows us to consider only a more restricted notion of what $A_{i}$ is, leaving open the possibility that there continue to be other unobserved elements of "personality" or "disposition" that are not being taken into account. $^{26}$

\footnotetext{
25 A similar argument pertains to unobserved job characteristics related to both harassment and job satisfaction.

26 Psychologists have developed a number of ways of conceptualizing the notion of personality (see Winter and Barenbaum, 1999 for a review of the history of modern personality theory). For example, the five-factor model postulates that five independent categories (extroversion, agreeableness, conscientiousness, neuroticism, and openness to experience) are sufficient to describe individual personality differences (see John and Srivastava, 1999; McCrae and Costa, 1999). Our data do not allow us to measure these aspects of individuals' personalities directly. Rather our approach is to take into account unobserved, time-invariant individual-specific effects that we ascribe to "personality".
} 


\subsection{A bivariate probit model}

Omitting $A_{i}$ from the model opens up the possibility of omitted variable bias because $\operatorname{Cov}\left(H_{i j}, \eta_{i j k}\right) \neq 0$. One solution is to re-estimate Eqs. (2) and (4) using a bivariate probit model that accounts for the possible correlation in the unobserved determinants of job satisfaction and reported sexual harassment. ${ }^{27,28}$ For the model to be identified, $X_{i}$ must contain at least one extra variable not contained in $Z_{i}$. Bivariate probit models are sensitive to the choice of exclusion restrictions ${ }^{29}$; however, raising questions about whether we can sensibly exclude certain variables from Eq. (4). We begin by investigating this issue.

\subsubsection{Investigating the validity and power of our instruments}

Relying on the results in Tables 1 and 2 and in the previous literature, we considered ship-based duty and marital status as exclusion restrictions. However, investigation led us to conclude that we do not have valid instruments that are powerful enough to detect the effect of sexually harassing behaviors on the intention to remain in the military. Thus, we focus our attention on estimating the bivariate probit model only for the job satisfaction equation.

In order to be valid our instruments must be, first, related to the probability of reporting sexually harassing behaviors and, second, unrelated to job satisfaction/dissatisfaction with military employment. Demonstrating the first proposition is straightforward. In Table 2, both marital status and current ship duty are, in general, individually significant at the 1 percent level irrespective of type of sexually harassing behavior considered. ${ }^{30}$ In all cases, the instruments are jointly significant at less than the 1 percent level. ${ }^{31}$

Can these instruments legitimately be excluded from the model of job satisfaction? While we see no compelling theoretical argument for including these variables in the job satisfaction model, there is also no compelling theoretical reason for excluding them and the matter is largely an empirical issue. To explore this we re-estimated Eq. (3) with marital status and ship duty in the job (dis)satisfaction equations. Though not a formal test, this does provide an indication of the patterns in the underlying data (see Evans and Schwab, 1995). In all cases, these variables were neither individually nor jointly significant at the 10 percent level. ${ }^{32}$

\footnotetext{
27 Evans and Schwab (1995) use a bivariate probit model to estimate the returns to Catholic education.

28 The triangular nature of the model implies that the simultaneity can be ignored and the model consistently estimated using a seemingly unrelated regressions model such as the bivariate probit.

29 Manski et al. (1992) and Painter and Levine (2000) discuss the sensitivity of bivariate probit models to the exclusion restrictions.

30 The exception is that current ship status is significant at only 5 percent in the sexual coercion equation.

31 Finite sample bias does not appear to be a concern in our model (see Bound et al., 1995). The $F$-statistics for the instruments from an OLS regression of the first-stage equation are $92.12(p=0.000), 218.69(p=0.000)$, and 70.85 ( $p=0.000)$ for our three measures of sexually harassing behaviors.

32 Overidentification tests can also be used to evaluate whether the proposed instruments can sensibly be excluded from the job satisfaction equations. In practice 2 SLS estimates are very close to the marginal effects generated by a bivariate probit model (Angrist, 1991). Given this, we follow Evans and Schwab in adopting a chi-squared overidentification test (see Hausman, 1983). The resulting test statistics were less than 0.15 , strongly supporting our exclusion restrictions.
} 
We also considered whether our instruments are powerful enough to detect an effect of sexual harassment on job dissatisfaction. Evans et al. (1999) discuss a method for calculating the change in the probability of a positive outcome that a discrete instrument must generate in order to detect a statistically significant 2SLS coefficient of a certain magnitude. Although not a formal test of the power of the instruments in a bivariate probit model, this calculation sheds light on this issue because of the correspondence in 2SLS and bivariate probit estimates. ${ }^{33}$

To illustrate consider the effect of any sexual harassment on the probability of being (very) dissatisfied with military employment. Given our sample size, we calculate that marital status must generate at least a 19.7 percentage point change in the probability of reporting one or more sexually harassing behaviors in order for us to detect an effect of sexual harassment on job dissatisfaction of the magnitude (0.053) reported in Table 3 at the 5 percent level. In our data, however, 62.9 percent of married and 73.3 percent of single women report some form of sexual harassment, a difference of 10.4 percentage points, so if the effect of any sexual harassment on the probability of being (very) dissatisfied were 5.3 percentage points (as we estimated using a standard probit model) we would not be able to detect it in a 2SLS model at the 5 percent level using marital status as our sole instrument. However, this calculation reveals that we would detect such an effect at the 20-30 percent significance level.

We repeated these calculations for each proposed instrument in the job (dis)satisfaction equations using all three definitions of sexually harassing behavior. The significance levels at which we would begin to detect estimated effects of the same magnitude as in Table 3 are given in Appendix A. This exercise indicates that marital status is a more powerful instrument than ship duty in identifying the effects of sexual harassment on job satisfaction. In all cases marital status would be powerful enough on its own to detect an estimated effect with at least a 30 percent level of confidence. Ship duty is a predictor of all types of sexually harassing behaviors, but because very few women in the sample (3.6 percent) actually serve on a ship, it is not powerful enough on its own to act as a sensible instrument. ${ }^{34}$ Given this, we conclude that ship duty and marital status serve as sensible exclusion restrictions in the bivariate probit model.

\subsubsection{Estimation results}

Selected marginal effects (and their associated standard errors and $p$-values) from the bivariate probit model are presented in columns 1 and 2 of Table 4, while the estimated correlation in the errors are presented in column 3. ${ }^{35}$ Results indicate that experiencing a sexually harassing behavior, regardless of the degree of severity, does not significantly affect dissatisfaction with military employment once the correlation in the unobserved fac-

\footnotetext{
${ }^{33}$ Details are presented in Appendix A. These calculations are conservative as they focus on the power of each instrument in isolation.

${ }^{34}$ Repeating these calculations for the intended job change indicates that it is more difficult to find instruments for these equations because, first, the effect of sexual harassment on intentions towards military employment is smaller (see Table 3), requiring more powerful instruments, and second, marital status cannot be excluded from this equation.

35 Marginal effects were calculated for each individual and then averaged. Standard errors were calculated using the "delta" method. The independent variables in the regression are defined as in Tables 2 and 3.
} 
Table 4

The effect of sexually harassing behaviors on job satisfaction

\begin{tabular}{|c|c|c|c|c|c|c|}
\hline \multirow[t]{2}{*}{ Prob (measure of job satisfaction) } & \multirow{2}{*}{$\begin{array}{l}\text { Measure of sexually } \\
\text { harassing behavior }\end{array}$} & \multicolumn{3}{|l|}{ Bivariate probit } & \multicolumn{2}{|l|}{$2 S L S$} \\
\hline & & Marginal effect (S.E.) & $P>|z|$ & Rho (S.E.) & Coefficient (S.E.) & $P>|z|$ \\
\hline (Very) dissatisfied with job ${ }^{\mathrm{a}}$ & Any sexually harassing behavior & $0.014(0.058)$ & 0.805 & $0.104(0.143)$ & $0.052(0.059)$ & 0.382 \\
\hline (Very) satisfied with job ${ }^{\mathrm{b}}$ & Any sexually harassing behavior & $0.005(0.067)$ & 0.946 & $-0.155(0.115)$ & $-0.067(0.074)$ & 0.368 \\
\hline (Very) dissatisfied with job ${ }^{\mathrm{a}}$ & Sexual attention/coercion & $0.044(0.040)$ & 0.235 & $0.000(0.093)$ & $0.036(0.038)$ & 0.346 \\
\hline (Very) satisfied with job ${ }^{\mathrm{b}}$ & Sexual attention/coercion & $-0.055(0.048)$ & 0.234 & $-0.019(0.081)$ & $-0.045(0.048)$ & 0.355 \\
\hline (Very) dissatisfied with job ${ }^{\mathrm{a}}$ & Sexual coercion & $-0.004(0.046)$ & 0.925 & $0.170(0.105)$ & $0.103(0.109)$ & 0.344 \\
\hline (Very) satisfied with job ${ }^{\mathrm{b}}$ & Sexual coercion & $-0.053(0.069)$ & 0.433 & $-0.097(0.100)$ & $-0.127(0.137)$ & 0.355 \\
\hline
\end{tabular}

Note: Independent variables as defined in Table 3.

${ }^{a}$ Relative to very satisfied, satisfied, and neither satisfied nor dissatisfied.

${ }^{\mathrm{b}}$ Relative to very dissatisfied, dissatisfied, and neither satisfied nor dissatisfied. 
tors associated with reported sexual harassment and job satisfaction are taken into account. We also present 2SLS estimates of the effect of reported unwanted gender-related behaviors (presented in columns 4 and 5 of Table 4) that reinforce the conclusions drawn from the bivariate probit model. Thus, it appears that single-equation estimates of the effect of experiencing sexually harassing behaviors on job satisfaction are overstated due to omitted variable bias resulting from the failure to control for unobserved heterogeneity.

Note that the $p$-value for the estimated coefficient in the job satisfaction and dissatisfaction equations is between 0.234 and 0.946 , which is higher than the calculated power of our instruments reported in Appendix A, so for example, we calculate that marital status would have been powerful enough on its own to detect the effect of sexual attention/coercion on job dissatisfaction between the 10 and 20 percent significance level. However, the $p$-value on this coefficient in the bivariate probit model is 0.235 , while the $p$-value in the 2SLS model is 0.346 . Thus, if the true effect of experiencing sexually harassing behaviors on job dissatisfaction had been as large as reported in Table 3, we would have been able to detect it given our exclusion restrictions. The insignificant relationships between sexually harassing behaviors and job (dis)satisfaction reported in Table 4 do not appear to be strictly due to weak instruments.

\subsection{Directly controlling for personality traits}

Once we take into account unobserved heterogeneity, unwanted gender-related behaviors do not result in reduced job satisfaction. Can we say anything about which unobserved characteristics might matter? In an attempt to answer this question, we re-estimate our satisfaction with and intentions to remain in military employment equations by adding a direct measure of whether women label their experiences as sexual harassment. While certainly not the only variable of interest, it seems sensible that women's perceptions of the behaviors they report are important in understanding the consequences of those experiences.

Women who report any form of sexually harassing behavior in the previous 12 months were asked whether they considered this experience to in fact be sexual harassment. Not all female military personnel who report experiencing 1 or more of the 18 behaviors listed in Table 1 consider themselves to have been the victim of sexual harassment. Overall, 67.3 percent of women reporting any sexually harassing behavior believe that they were sexually harassed. Not surprisingly, the more severe the behavior, the more likely women are to consider the behavior to be sexual harassment. Specifically, 80.4 percent of women reporting either sexual attention or coercion viewed this as sexual harassment, while 91.6 percent of those experiencing sexual coercion labeled applied sexual harassment label. ${ }^{36}$ Though direct comparisons are difficult, women in the US military appear to be less likely to label specific behaviors as sexual harassment than are their female counterparts in parts of the US Government (USMSPB).

We use this additional information to control directly for unobserved "personality" or "disposition" in single-equation models of satisfaction with and intentions to remain in

\footnotetext{
36 While we attempt to control for severity, it is possible that even within a particular category (say sexual coercion) some behaviors may be less severe than others, leading women to be less inclined to see them as sexual harassment.
} 
military employment. ${ }^{37}$ This allows us to focus on two questions. First, conditional on the actual behavior a woman reports experiencing, are there additional negative consequences associated with seeing those experiences as sexual harassment? Second, does controlling for women's views of sexual harassment affect estimates of the effect of the behavior itself on job satisfaction and intended job change? These estimation results (marginal effects and standard errors) are presented in Table 5. Model 1 only includes controls for individuals' views about whether they have been sexually harassed. Models $2-4$ add additional controls for the actual behavior experienced using our previous measures that allow for differing degrees of severity.

Believing that one has been sexually harassed is associated with lower job satisfaction and a heightened intention to leave the military (see model 1). These results are very similar to previous estimates of the effect of experiencing any form of sexually harassing behavior on job (dis)satisfaction and intentions to leave/remain in the military (see rows $1-4$, Table 3 ). Also controlling for the harassing behavior itself reduces this estimate somewhat. Still, it remains the case that women who see themselves as sexually harassed are significantly more likely to be dissatisfied with and intend to leave military employment than women who do report experiencing one or more of the sexually harassing behaviors, but do not consider it to be sexual harassment. Controlling for reported sexual attention/coercion, for example, we find that women who view their experiences as sexual harassment are 4.2 percentage points more likely to be (very) dissatisfied with their jobs and 1.8 percentage points more like to be (very) unlikely to remain in the military. These results are in sharp contrast to previous research suggesting that outcomes do not differ for those who do and do not label their experiences (Magley et al.).

Additionally, directly controlling for women's views results in smaller estimated effects of the actual behaviors themselves. For example, female personnel experiencing any form of sexual harassing behavior are 5.3 percentage points more likely to be (very) dissatisfied with their military jobs than women who experience no such behaviors (see Table 3 ). Once we control for whether they viewed this behavior as sexual harassment, this difference falls to 3.3 percentage points. In all cases, the estimated effect of sexually harassing behaviors falls in absolute value once we control for whether the respondent considered herself to be sexually harassed. In fact, there is only weak evidence that sexual harassing behaviors per se influence women's propensity to either leave or remain in the US military (see Table 5). Women's views about whether they have experienced sexual harassment are more closely related to intentions towards future military employment.

In light of this, it is interesting to ask who considers herself to be sexually harassed? To answer this, we restrict our sample to those women reporting some form of sexually harassing behavior and use a probit model to estimate the determinants of whether she considered that behavior to be sexual harassment (see Table 6). Not surprisingly, female active-duty personnel are more likely to consider themselves to be sexually harassed if they experienced sexual attention/coercion than if they were subjected solely to crude and offensive behavior.

\footnotetext{
37 This measure equals 1 for women reporting that they experienced 1 or more sexually harassing behaviors and considered it to have been sexual harassment. It is equal to 0 for women reporting no specific incidents of sexually harassing behavior or for women who do report experiencing 1 or more of the 18 sexually harassing behaviors surveyed, but indicate they have not been subject to sexual harassment.
} 
Table 5

The effect of considered sexual harassment on job satisfaction (probit marginal effects and standard errors)

\begin{tabular}{|c|c|c|c|c|c|c|c|c|}
\hline & \multicolumn{2}{|l|}{ Model 1} & \multicolumn{2}{|l|}{ Model 2} & \multicolumn{2}{|l|}{ Model 3} & \multicolumn{2}{|l|}{ Model 4} \\
\hline & $\begin{array}{l}\text { Marginal } \\
\text { effect }\end{array}$ & $\begin{array}{l}\text { Standard } \\
\text { error }\end{array}$ & $\begin{array}{l}\text { Marginal } \\
\text { effect }\end{array}$ & $\begin{array}{l}\text { Standard } \\
\text { error }\end{array}$ & $\begin{array}{l}\text { Marginal } \\
\text { effect }\end{array}$ & $\begin{array}{l}\text { Standard } \\
\text { error }\end{array}$ & $\begin{array}{l}\text { Marginal } \\
\text { effect }\end{array}$ & $\begin{array}{l}\text { Standard } \\
\text { error }\end{array}$ \\
\hline \multicolumn{9}{|l|}{ (Very) dissatisfied with job ${ }^{a}$} \\
\hline View as sexual harassment & $0.052^{* * *}$ & $(0.006)$ & $0.033^{* * *}$ & $(0.007)$ & $0.042^{* * * *}$ & $(0.006)$ & $0.043^{* * *}$ & $(0.006)$ \\
\hline Any sexually harassing behavior & & & $0.033^{* * *}$ & $(0.007)$ & & & & \\
\hline Sexual attention/coercion & & & & & $0.021^{* * *}$ & $(0.007)$ & & \\
\hline Sexual coercion & & & & & & & $0.055^{* * *}$ & $(0.010)$ \\
\hline \multicolumn{9}{|l|}{ (Very) satisfied with job ${ }^{b}$} \\
\hline View as sexual harassment & $-0.081^{* * *}$ & $(0.007)$ & $-0.050^{* * *}$ & $(0.009)$ & $-0.064^{* * *}$ & $(0.008)$ & $-0.067^{* * *}$ & $(0.007)$ \\
\hline $\begin{array}{l}\text { Any sexually harassing behavior } \\
\text { Sexual attention/coercion }\end{array}$ & & & -0.056 & (0.009) & $-0.036^{* * *}$ & $(0.009)$ & & \\
\hline Sexual coercion & & & & & & & $-0.092^{* * *}$ & $(0.013)$ \\
\hline \multicolumn{9}{|l|}{ (Very) unlikely to remain ${ }^{\mathrm{c}}$} \\
\hline View as sexual harassment & $0.023^{* * *}$ & $(0.006)$ & $0.021^{* *}$ & $(0.008)$ & $0.018^{* *}$ & $(0.007)$ & $0.021^{* * *}$ & $(0.007)$ \\
\hline Any sexually harassing behavior & & & 0.005 & $(0.009)$ & & & & \\
\hline Sexual coercion & & & & & & & $0.019^{*}$ & $(0.012)$ \\
\hline \multicolumn{9}{|l|}{ (Very) likely to remain ${ }^{\mathrm{d}}$} \\
\hline View as sexual harassment & $-0.042^{* * *}$ & $(0.007)$ & $-0.037^{* * *}$ & $(0.009)$ & $-0.033^{* * *}$ & $(0.008)$ & $-0.039^{* * *}$ & $(0.008)$ \\
\hline Any sexually harassing behavior & & & -0.010 & $(0.010)$ & & & & \\
\hline Sexual attention/coercion & & & & & $-0.020^{* *}$ & $(0.009)$ & & \\
\hline Sexual coercion & & & & & & & $-0.024^{*}$ & $(0.013)$ \\
\hline
\end{tabular}

Note: Independent variables as defined in Table 3. The number of observations is 19,232.

a Relative to very satisfied, satisfied, and neither satisfied nor dissatisfied.

${ }^{\mathrm{b}}$ Relative to very dissatisfied, dissatisfied, and neither satisfied nor dissatisfied.

c Relative to very likely, likely, and neither likely nor unlikely.

d Relative to very unlikely, unlikely, and neither likely nor unlikely.

* Significant at less than 10 percent.

** Significant at less than 5 percent.

*** Significant at less than 1 percent. 
Table 6

Determinants of viewing sexually harassing behavior as "sexual harassment" (probit marginal effects and standard errors)

\begin{tabular}{|c|c|c|}
\hline & Marginal effects & Standard errors \\
\hline Sexual attention/coercion & $0.242^{* * *}$ & $(0.009)$ \\
\hline Sexual coercion & $0.198^{* * *}$ & $(0.012)$ \\
\hline \multicolumn{3}{|c|}{ Demographic and human capital characteristics } \\
\hline Married & $0.026^{* * *}$ & $(0.009)$ \\
\hline Black & $-0.029^{* * *}$ & $(0.011)$ \\
\hline Hispanic & 0.022 & $(0.022)$ \\
\hline Other & -0.000 & $(0.020)$ \\
\hline Years of duty & 0.005 & $(0.003)$ \\
\hline Years of duty squared & -0.000 & $(0.000)$ \\
\hline \multicolumn{3}{|l|}{ Education } \\
\hline Less than BA & $0.048^{* * *}$ & $(0.014)$ \\
\hline BA & $0.045^{* *}$ & $(0.020)$ \\
\hline Greater than BA & 0.036 & $(0.022)$ \\
\hline \multicolumn{3}{|l|}{ Current job characteristics } \\
\hline Service & & \\
\hline Navy & $-0.061^{* * * *}$ & $(0.013)$ \\
\hline Marines & $-0.034^{* *}$ & $(0.017)$ \\
\hline Air Force & $-0.077^{* * *}$ & $(0.012)$ \\
\hline Coast Guard & $-0.038^{*}$ & $(0.021)$ \\
\hline Male supervisor & $0.032^{* * * *}$ & $(0.012)$ \\
\hline \multicolumn{3}{|l|}{ Gender mix of work group } \\
\hline Male dominated & $0.059^{* * *}$ & $(0.013)$ \\
\hline Female dominated & $0.041^{* * *}$ & $(0.015)$ \\
\hline \multicolumn{3}{|l|}{ Pay scale } \\
\hline E1-E3 & 0.002 & $(0.034)$ \\
\hline E4 & 0.015 & $(0.029)$ \\
\hline E5-E6 & -0.037 & $(0.024)$ \\
\hline E7-E9 & -0.039 & $(0.025)$ \\
\hline W1 & 0.001 & $(0.043)$ \\
\hline $\mathrm{O} 1-\mathrm{O} 3$ & -0.031 & $(0.021)$ \\
\hline MOS uncommon for gender & $0.061^{* * *}$ & $(0.013)$ \\
\hline Supervisor & 0.004 & $(0.010)$ \\
\hline Located in US & -0.022 & $(0.012)$ \\
\hline In training-related duty & 0.004 & $(0.011)$ \\
\hline Serving on a ship & -0.011 & $(0.023)$ \\
\hline \multicolumn{3}{|l|}{ Duty station has } \\
\hline Sexual harassment hotline & -0.012 & $(0.011)$ \\
\hline Sexual harassment office & 0.013 & $(0.010)$ \\
\hline Complaint process & $-0.061^{* * *}$ & $(0.011)$ \\
\hline Sexual harassment training & $-0.055^{* * *}$ & $(0.010)$ \\
\hline$N$ & 12,954 & \\
\hline
\end{tabular}

Note: See the text for variable definitions.

* Significant at less than 10 percent.

** Significant at less than 5 percent.

*** Significant at less than 1 percent. 
More specifically, women experiencing sexual attention are 24.2 percentage points more likely to believe that they were sexually harassed, while women experiencing sexual coercion are 44 percentage points more likely than other women to view their experiences as sexual harassment. ${ }^{38}$ Furthermore, female active-duty personnel are more likely to consider themselves to be sexually harassed if they are in a work group where the gender mix is not equal. Relative to the Army, women in all other service types are less likely to consider themselves to be sexually harassed.

Interestingly, women with at least $1 \mathrm{~h}$ of sexual harassment training are less likely to report experiencing sexually harassing behavior (see Table 2), but given that they do report one or more sexually harassing behavior, they are less likely to believe that they have in fact been sexually harassed. This raises the possibility that training itself may reduce the incidence of unwanted gender-related behavior while at the same time mitigating the negative consequences of that behavior by altering women's perceptions. ${ }^{39}$ Still, there is little direct evidence in the literature that preventative measures such as sexual harassment training serve to alter individuals' behavior. Although all agencies within the US Federal Government (including the US military) provide training in preventing, recognizing, and handling sexual harassment, no formal evaluation of these programs has taken place. Survey results from civilian employees indicate that workers participating in sexual harassment training find it to be a positive experience, but not overwhelmingly so. While 65 percent report that the training made them more sensitive to the issue of sexual harassment, one in five indicated that it had no effect on their attitudes or beliefs at all (USMSPB), individuals participating in training have more expansive definitions of the behaviors that constitute sexual harassment (Antecol and Cobb-Clark, 2003). Perhaps more important in reducing the incidence of sexual harassment might be the focus on proactive measures to avoid and deal with sexual harassment that are important components of the sexual harassment training provided to military personnel (U.S. Army, 2001).

\section{Conclusions}

This paper examines the relationship between sexual harassment, job satisfaction and intended job change using data from a 1995 US DoD survey of active-duty women serving in the military. Overall, 70.9 percent of women on active-duty in the US military report experiencing some type of sexually harassing behavior in the 12 months prior to the survey. Using single-equation probit models we find a strong positive relationship between experiencing a sexually harassing behavior and dissatisfaction with military employment and intention to leave the military. These results are consistent with previous results for women employed as lawyers in the US (Laband and Lentz).

\footnotetext{
${ }^{38}$ To see this, note that given the way in which the model is parameterized, the total effect of sexual coercion on perceptions of sexual harassment is the sum of the effect of sexual attention/sexual coercion and sexual coercion reported in Table 6.

${ }^{39}$ Research indicates that impartial observers see the severity of sexual harassment to be less in situations where the harasser offers an apology to the victim (Hunter and McClelland, 1991). If this extends to victims' perceptions as well, training could help reduce the negative consequences of harassment if it results in victims being more successful in extracting apologies.
} 
However, unobserved heterogeneity in individual characteristics causes single-equation estimates of the effect of sexually harassing behavior to be overstated. This heterogeneity may stem from aspects of an individual's personality (including perceptions of, tolerance for, or willingness to report unpleasant events in the workplace) that are likely to affect both reports of sexually harassing behaviors and women's satisfaction with military employment. Once the correlation in the unobserved factors associated with reporting sexual harassment and job satisfaction are taken into account, experiencing a sexually harassing behavior does not in and of itself significantly increase dissatisfaction with military employment. Furthermore, women's views about the unwanted gender-related behaviors they experience are closely related to subsequent outcomes. Women who view their experiences as sexual harassment have significantly higher levels of overall job dissatisfaction and heightened intentions to leave the military than women who experience unwanted, gender-related behavior, but who do not believe themselves to have been sexually harassed. The estimated negative effect of the sexually harassing behavior itself on overall job satisfaction is substantially reduced (and the effect on intentions to remain in military employment eliminated) once these views are taken into account.

\section{Acknowledgements}

The authors would like to thank the participants of the 2001 Labour Econometrics Workshop in Sydney Australia for helpful comments. None of the views expressed in this paper represent the official views of the U.S. Department of Defense.

\section{Appendix A}

This appendix outlines the procedure used to calculate the power of our proposed binary instruments. We have modified the calculation suggested by Evans et al. (1999) to allow for the unequal numbers of individuals for whom the instrument takes positive and 0 values. ${ }^{40}$

To illustrate, consider the following bivariate regression model:

$$
y_{i}=\alpha+\beta x_{i}+\varepsilon_{i}
$$

where $y_{i}$ is our measure of job dissatisfaction and $x_{i}$ is a discrete measure of sexual harassment. Let $z_{i}$ be a binary instrument (i.e., marital status or ship duty). The IV estimate of $\beta$ is the same as the Wald estimate used in the evaluation literature (Angrist, 1990) and is given by

$$
\beta_{\mathrm{IV}}=\frac{\left(\bar{y} \mid z_{i}=1\right)-\left(\bar{y} \mid z_{i}=0\right)}{\left(\bar{x} \mid z_{i}=1\right)-\left(\bar{x} \mid z_{i}=0\right)}=\frac{\bar{y}_{1}-\bar{y}_{0}}{\bar{x}_{1}-\bar{x}_{0}}=\frac{\delta_{1}}{\delta_{2}}
$$

\footnotetext{
$\overline{40}$ In order to simplify the calculation these authors assume that the number of individuals for whom the instrument takes the value of 1 equals the number for whom the instrument equals 0 . In our case, this is not a realistic assumption because only 3.4 percent of the active-duty women in our sample are currently serving on ships.
} 
where $\bar{y}_{1}=(y \mid z=1)$ is the mean of $y_{i}$ for those individuals with $z_{i}=1$ and $\bar{y}_{0}, \bar{x}_{1}$, and $\bar{x}_{0}$ are defined in a similar fashion. The numerator $\left(\delta_{1}\right)$ in the above expression is calculated from a regression of job dissatisfaction $(y)$ on our proposed instrument $(z)$, and the statistical significance of the resulting coefficient drives the statistical significance of the 2SLS estimate.

Let $n_{1}$ equal the number of individuals for whom $z=1$ and $n_{0}$ equal the number of individuals for whom $z=0$ with $n_{1}+n_{0}=n$. This implies that

$$
\bar{y}=\frac{n_{1}}{n} \bar{y}_{1}+\frac{n_{0}}{n} \bar{y}_{0} .
$$

Rearranging Eq. (3) first to solve for $\bar{y}_{1}$ and then again for $\bar{y}_{0}$ results in the following:

$$
\begin{aligned}
& \bar{y}_{1}=\bar{y}+\frac{n_{0}}{n} \delta_{1} \\
& \bar{y}_{0}=\bar{y}-\frac{n_{1}}{n} \delta_{1}
\end{aligned}
$$

with

$$
\operatorname{Var}\left(\delta_{1}\right)=\operatorname{Var}\left(\bar{y}_{1}-\bar{y}_{0}\right)=\frac{\bar{y}_{1}\left(1-\bar{y}_{1}\right)}{n_{1}}+\frac{\bar{y}_{0}\left(1-\bar{y}_{0}\right)}{n_{0}} .
$$

Substituting Eq. (4) into Eq. (5) results in the following expression for the variance of $\delta_{1}$ :

$$
\operatorname{Var}(\delta 1)=A \delta_{1}^{2}+B \delta_{1}+C
$$

where

$$
\begin{aligned}
& A=-\frac{n_{0}^{2}}{n^{2} n_{1}}-\frac{n_{1}^{2}}{n^{2} n_{0}} \\
& B=(1-2 \bar{y})\left[\frac{n_{0}}{n n_{1}}-\frac{n_{1}}{n n_{0}}\right] . \\
& C=\bar{y}(1-\bar{y})\left[\frac{1}{n_{1}}+\frac{1}{n_{0}}\right]
\end{aligned}
$$

Whenever the following holds, $\delta_{1}$ will be statistically significant at the 5 percent level:

$$
\begin{aligned}
& \left|\delta_{1}\right|>1.96 \cdot \sqrt{\operatorname{Var}\left(\delta_{1}\right)} \\
& \left|\delta_{1}\right|>M
\end{aligned} .
$$

Since $\delta_{1}=\beta_{\mathrm{IV}} \delta_{2}$ we can use the above expression to address the following question: for a $\beta_{\mathrm{IV}}$ of a particular magnitude (which we take to be the single-equation estimates presented in Table 3), how much must the instrument change the probability of observing the endogenous variable (i.e., how large must $\delta_{2}$ be) in order to generate an estimate of $\delta_{1}$ that is significant at 5 percent? The answer is given by

$$
\left|\delta_{2}\right|>\frac{M}{\left|\beta_{\mathrm{IV}}\right|} .
$$

In other words, to identify a statistically significant reduced-form estimate between $y$ and $z$ of a size comparable to the single-equation estimates in Table 3, the discrete instrument 
Table A.1

Power of instruments

\begin{tabular}{|c|c|c|c|}
\hline \multirow[t]{2}{*}{$\begin{array}{l}\text { Prob (measure of job } \\
\text { satisfaction) }\end{array}$} & \multirow[t]{2}{*}{$\begin{array}{l}\text { Measure of sexually } \\
\text { harassing behavior }\end{array}$} & \multicolumn{2}{|c|}{$\begin{array}{l}\text { Significance level at which estimated } \\
\text { effect would be detected }\end{array}$} \\
\hline & & Ship status (percent) & Married (percent) \\
\hline (Very) dissatisfied with job ${ }^{\mathrm{a}}$ & Any sexually harassing behavior & $>30$ & $20-30$ \\
\hline (Very) satisfied with job ${ }^{b}$ & Any sexually harassing behavior & $>30$ & $10-20$ \\
\hline (Very) dissatisfied with job ${ }^{\mathrm{a}}$ & Sexual attention/coercion & $>30$ & $10-20$ \\
\hline (Very) satisfied with job ${ }^{b}$ & Sexual attention/coercion & $>30$ & $5-10$ \\
\hline (Very) dissatisfied with job ${ }^{\mathrm{a}}$ & Sexual coercion & $>30$ & $20-30$ \\
\hline (Very) satisfied with job ${ }^{b}$ & Sexual coercion & $>30$ & $20-30$ \\
\hline
\end{tabular}

Note: In each case the magnitude of the effect is taken to be that which would be generated from a single equation probit model ignoring endogeneity. These estimates are given in Table 3.

${ }^{a}$ Relative to very satisfied, satisfied, and neither satisfied nor dissatisfied.

b Relative to very dissatisfied, dissatisfied, and neither satisfied nor dissatisfied.

for $x$ must change the probability of reporting sexual harassing behaviors by at least the amount given in Eq. (9).

These calculations highlight the relationships between sample size, the proportion of the population with $z=1$, the magnitude of the effect of $z$ on $y$, and the relationship between the $z$ and $x$ in detecting significant effects using IV regression. Everything else equal, significant effects are, not surprisingly, more likely to be detected when overall sample sizes are larger and when the magnitude of the effect to be detected $\left(\beta_{\text {IV }}\right)$ is larger. Similarly, significant effects are also more likely to be detected when the population is evenly split between those individuals for whom the instrument takes on the value of 1 and those for whom it takes on a value of 0 . Finally, there is a positive relationship between the power of the instrument to predict the endogenous $x$ variable and probability of detecting significant effects (Table A.1).

\section{References}

Angrist, J.D., 1990. Lifetime earnings and the Vietnam era draft lottery: evidence from social security administrative records. American Economic Review 80, 313-336.

Angrist, J.D., 1991. Instrumental variables estimation of average treatment effects in econometrics and epidemiology. NBER technical working paper no. 115.

Antecol, H., Cobb-Clark, D.A., 2001. Men, women, and sexual harassment in the U.S. military. Gender Issues 19 , $3-18$.

Antecol, H., Cobb-Clark, D.A., 2003. Does sexual harassment training change attitudes? A view from the federal level. Social Science Quarterly 84, 826-842.

Arvey, R.D., Cavanaugh, M.A., 1995. Using surveys to assess the prevalence of sexual harassment: some methodological problems. Journal of Social Issues 51, 39-52.

Bartel, A.P., 1981. Race differences in job satisfaction: a reappraisal. Journal of Human Resources 16, $294-303$.

Bastian, L.D., Lancaster, A.R., Reyst, H.E., 1996. Defense Manpower Data Center Report No. 96-014. Department of Defense 1995 Sexual Harassment Survey.

Basu, K., 2002. Sexual harassment in the workplace: an economics analysis with implications for worker rights and labor standards policy. Unpublished paper. Massachusetts Institute of Technology (available at http://papers.ssrn.com/sol3/papers.cfm?abstract_id=303184). 
Basu, K., 2003. The economics and law of sexual harassment in the workplace. Journal of Economic Perspectives 17, 141-157.

Bertrand, M., Mullainathan, S., 2001. Do people mean what they say? Implications for subjective survey data. American Economic Review 91, 67-72.

Bound, J., Jaeger, D.A., Baker, R., 1995. Problems with instrumental variables estimation when the correlation between the instruments and the endogenous explanatory variable is weak. Journal of the American Statistical Association 90, 443-450.

Clark, A.E., 1996. Job satisfaction in Britain. British Journal of Industrial Relations 34, 189-217.

Clark, A.E., 1997. Job satisfaction and gender: why are women so happy at work? Labour Economics 4, 314 372.

Clark, A.E., 2001. What really matters in a job? Hedonic measurement using quit data. Labour Economics 8, $223-242$.

Clark, A.E., Oswald, A.J., 1996. Satisfaction and comparison income. Journal of Public Economics 61, 359-381.

Clark, A.E., Gerogellis, Y., Sanfey, P., 1998. Job satisfaction, wage changes, and quits: evidence from Germany. Research in Labour Economics 17, 95-121.

Clegg, C.W., 1983. Psychology of employee lateness, absence, and turnover: a methodological critique and an empirical study. Journal of Applied Psychology 68, 88-101.

Department of Defense (DoD), 1996. News Briefing by Edwin Dorn, USD, Personnel and Readiness, July 2.

Evans, W.N., Farrelly, M.C., Montgomery, E., 1999. Do workplace smoking bans reduce smoking. American Economic Review 89, 728-747.

Evans, W.N., Schwab, R.M., 1995. Finishing high school and starting college: do Catholic schools make a difference? Quarterly Journal of Economics 110, 941-974.

Fitzgerald, L.F., Drasgow, F., Hulin, C.L., Gelfand, M.J., Magley, V.J., 1997. Antecedents and consequence of sexual harassment in organizations: a test of an integrated model. Journal of Applied Psychology 82, 578-589.

Fitzgerald, L.F., Magley, V.J., Drasgow, F., Waldo, C.R., 1999. Measuring sexual harassment in the military: the Sexual Experiences Questionnaire (SEQ-DoD). Military Psychology 11, 247-263.

Freeman, R.B., 1978. Job satisfaction as an economic variable. American Economic Review 68, 135-141.

Gordon, M.E., Denisi, A.S., 1995. A re-examination of the relationship between union membership and job satisfaction. Industrial and Labor Relations Review 48, 222-236.

Hamermesh, D.S., 1977. Economics aspects of job satisfaction. In: Ashenfelter, O.E., Oates, W.E. (Eds.), Essays in Labor Market Analysis. John Wiley, New York, pp. 53-72.

Hausman, J., 1983. Specification and estimation of simultaneous equation models. In: Griliches, Z., Intriligator, M.D. (Eds.), Handbook of Econometrics, vol. 1. North-Holland, New York, pp. 392-448.

Hay, M.S., Elig, T.W., 1999. The 1995 Department of Defense Sexual Harassment Survey: overview and methodology. Military Psychology 11, 233-242.

Heywood, J.S., Wei, X. Performance pay and job satisfaction. Journal of Industrial Relations, in press.

Hunter, C., McClelland, K., 1991. Honoring accounts for sexual harassment: a factorial survey analysis. Sex Roles 24, 725-752.

John, O.P., Srivastava, S., 1999. The big five trait taxonomy: history, measurement, and theoretical perspectives. In: Pervin, L.A., John, O.P. (Eds.), Handbook of Personality: Theory and Research. The Guilford Press, New York, pp. 102-138.

Knouse, S.B., 1991. Introduction to racial, ethnic and gender issues in the military: the decade of the 1900s and beyond. International Journal of Intercultural Relations 15, 385-388.

Kristensen, N., Westergård-Neilsen, N., 2004. Does low job satisfaction lead to job mobility? IZA discussion paper no. 1026 (available at www.iza.org).

Laband, D.N., Lentz, B.F., 1998. The effects of sexual harassment on job satisfaction, earnings, and turnover among female lawyers. Industrial and Labor Relations Review 51, 594-607.

Lancaster, A.R., 1999. Department of Defense Sexual Harassment Survey: overview and methodology. Military Psychology 11, 219-231.

Locke, E.A., 1976. The nature and causes of job satisfaction. In: Dunnette, M. (Ed.), Handbook of Industrial and Organizational Psychology. Rand McNally, Chicago, pp. 1297-1349.

Magley, V.J., Hulin, C.L., Fitzgerald, L.F., DeNardo, M., 1999. Outcomes of self-labeling sexual harassment. Journal of Applied Psychology 84, 390-402. 
Mangione, T.W., Quinn, R.P., 1975. Job satisfaction, counterproductive behaviour and drug use at work. Journal of Applied Psychology 60, 114-116.

Manski, C.G., Sandefur, G.D., McLanahan, S., Powers, D., 1992. Alternative estimates of the effect of family structure during adolescence on high school graduation. Journal of the American Statistical Association 87, $25-37$.

McCrae, R.R., Costa Jr., P.T., 1999. A five-factor theory of personality. In: Pervin, L.A., John, O.P. (Eds.), Handbook of Personality: Theory and Research. The Guilford Press, New York, pp. 139-153.

Painter, G., Levine, D.I., 2000. Family structure and youths' outcomes: which correlations are causal? Journal of Human Resources 35, 524-549.

Rosen, L.N., Martin, L., 1997. Sexual harassment, cohesion and combat readiness in U.S Army support units. Armed Forces and Society 24, 221-244.

Schneider, K.T., Swan, S., Fitzgerald, L.F., 1997. Job-related and psychological effects of sexual harassment in the workplace: empirical evidence from two organizations. Journal of Applied Psychology 82, 401-515.

Shields, M.A., Wheatley Price, S., 2002. Racial harassment, job satisfaction and intentions to quit: evidence from the British nursing profession. Economica 69, 295-326.

Shields, M.A., Ward, M.E., 2001. Improving nurse retention in the National Health Service in England: the impact of job satisfaction on intentions to quit. Journal of Health Economics 20, 677-701.

Williams, J.H., Fitzgerald, L.F., Drasgow, F., 1999. The effects of organizational practices on sexual harassment and individual outcomes in the military. Military Psychology 11, 303-328.

Winter, D.G., Barenbaum, N.B., 1999. History of modern personality theory and research. In: Pervin, L.A., John, O.P. (Eds.), Handbook of Personality: Theory and Research. The Guilford Press, New York, pp. 3-27.

U.S. Army, 2001. Lesson 22: Prevention of Sexual Harassment (www.odcsper.army.mil).

U.S. Merit Systems Protection Board (USMSPB), 1995. Sexual Harassment in the Federal Workplace: Trends, Progress, Continuing Challenges. U.S. Government Printing Office, Washington, DC. 